\title{
Effects of Negotiated Interaction in L2 Acquisition: A Study in Tertiary Education in Bangladesh
}

By Asif Al Matin

Begum Rokeya University

Abstract- The process of $\mathrm{L} 2$ (Second language) acquisition is a complicated, conscious one that requires an understanding of $\mathrm{L} 2$ input to produce $\mathrm{L} 2$ output. Among different strategies, Negotiated Interaction is one way to improve L2 acquisition. Though Bangladesh is a monolingual country, in education system of Bangladesh, English plays an important role. Especially in tertiary education in Bangladesh, English is the dominating medium of teaching and learning. Tertiary education is the level after which usually students in Bangladesh go for searching different types of jobs, so Negotiated Interaction can be helpful to keep a balanced atmosphere of input and output for both the teachers and learners. Apart from some limitations, this strategy can be one of the most effective one in case of teaching and learning in the tertiary education in Bangladesh. The purpose of this article is to show how this strategy improves L2 acquisition. Negotiated Interaction can play an effective role in combining teaching and learning processes for $\mathrm{L} 2$ acquisition in tertiary education in Bangladesh.

Keywords: negotiated interaction, English as Second Language (ESL), English as Foreign Language (EFL), classroom activities, classroom environment, English Language Teaching (ELT).

GJHSS-G Classification: FOR Code: 339999

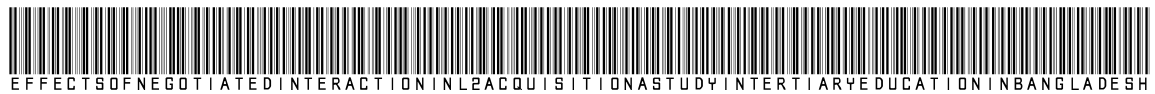

Strictly as per the compliance and regulations of:

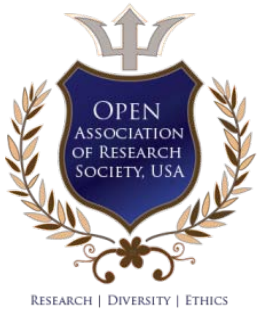

(C) 2021. Asif Al Matin. This is a research/review paper, distributed under the terms of the Creative Commons AttributionNoncommercial 3.0 Unported License http://creativecommons.org/licenses/by-nc/3.0/), permitting all non-commercial use, distribution, and reproduction in any medium, provided the original work is properly cited. 


\title{
Effects of Negotiated Interaction in L2 Acquisition: A Study in Tertiary Education in Bangladesh
}

\author{
Asif Al Matin
}

Abstract- The process of L2 (Second language) acquisition is a complicated, conscious one that requires an understanding of L2 input to produce L2 output. Among different strategies, Negotiated Interaction is one way to improve $\mathrm{L} 2$ acquisition. Though Bangladesh is a monolingual country, in education system of Bangladesh, English plays an important role. Especially in tertiary education in Bangladesh, English is the dominating medium of teaching and learning. Tertiary education is the level after which usually students in Bangladesh go for searching different types of jobs, so Negotiated Interaction can be helpful to keep a balanced atmosphere of input and output for both the teachers and learners. Apart from some limitations, this strategy can be one of the most effective one in case of teaching and learning in the tertiary education in Bangladesh. The purpose of this article is to show how this strategy improves $\mathrm{L} 2$ acquisition. Negotiated Interaction can play an effective role in combining teaching and learning processes for L2 acquisition in tertiary education in Bangladesh.

Keywords: negotiated interaction, English as Second Language (ESL), English as Foreign Language (EFL), classroom activities, classroom environment, English Language Teaching (ELT).

\section{INTRODUCTION}

N egotiated Interaction refers to a meaningful learner to learner, learner to teacher interaction in classroom where the learners have the flexibility and freedom to talk, not just react and respond to the subject. However, negotiated interaction means that the learner should be actively involved in the interaction as a textual, interpersonal, and ideational activity. Halliday (1985) categorized interaction into three classifications: textual, interpersonal, and ideational. Interaction as a textual activity refers to linguistic and metalinguistic features of language necessary for understanding language input. The linguistic dimension deals with phonological, syntactic, and semantic signals that enable learners and their interlocutors to understand input and transmit messages as intended. Interaction as an interpersonal activity refers to the use of language to promote communication between participants. Consequently, it involves sociolinguistic features of language required to establish roles, relationships, and responsibilities. Finally, interaction as an ideational

Author: Assistant Professor, Department of English, Begum Rokeya University, Rangpur, Bangladesh. e-mail: asifalmatin@gmail.com activity refers to an expression of the participants' own experience of the practices, people, events, and objects of the real or imaginary world inside and outside the situated learning and teaching context. Specifically, it focuses on ideas and emotions participants bring with them based on their life experiences, past and present. Kumaravadivelu (2007) believed that micro-strategies for facilitating negotiated interaction should provide opportunities for learners to stretch their linguistic knowledge, improve their conversational capacities, and share their individual experiences.

The impact of negotiated interaction can be different among learners and teachers. To get the real scenario, some points should be given much emphasis. Among those points we can start our analysis by learning environment. Classroom activities should be provided importance about the real life language usage. Learning opportunities should be emphasized by the teachers to ensure individual learning properly. Long (1996) claims that "negotiation of meaning and especially negotiation work that triggers interactional adjustments by the NS or more competent interlocutor, facilitates acquisition. (Pp.451-452).

\section{il. Literature ReVieW}

The study of classroom interaction commenced in the middle of the twentieth century. In this interaction sequence, the teacher often tightly controlled the structure and content of classroom interaction, initiated the discussion by posing questions to the learners. After getting answers from them, the teacher finished interactions sequence by giving feedback on the learners' responses. Literally, the practicing of the Grammar Translation Method (GTM) created awkward situations that hinder learning and teaching English as a foreign or second language though the rationale for the exclusive or near-exclusive use of the language has not been questioned at that time (Turnbull and Arnett, 2002).

The nature and purpose of the L2 interaction have evolved with each methodological development, however, and it was not until the widespread adoption of Communicative Language Teaching, or CLT, that real communication in L2 was firmly on the agenda (Nunan, 1991). The gradual change in focus from a transmission 
model of teaching to the learner-sensitive instruction, emphasizing collective negotiation in classroom interaction, went hand in hand with the theoretical shift in perspectives on learning and teaching to emphasize the active role of individuals in meaning-making and knowledge construction.

The spontaneity in language's talk is more about understanding and readiness of response than it is about the act of spoken production. An acquisition rich classroom is one in which there is a lot of linguistic input, made comprehensible by the teacher talk, if necessary resorting to several attempts to simplify the message. From the very beginning of language study, the classroom should be interactive. "Interaction and interactive language constitute a major role in EFL teaching because teachers' interactive language can keep an interaction going on smoothly in EFL classroom." (Ellis \& Barkhuizen, 2005, p. 165-227).

Classroom interaction involves the components of collaborative dialogue, negotiation, and coconstruction. Negotiated classroom interaction in the target language can now be seen as not just offering language practice, nor just learning opportunities, but as actually constructing the language development process itself. However, not all forms of negotiated classroom interaction are equally productive for language development. Ellis and Barkhuizen (2005) claim in the Interaction Hypothesis that when L2 learners face communicative problems and they have the opportunity to negotiate solutions to them, they can acquire new language. Negotiated interaction is essential for input to become comprehensible. It runs counter to Krashen's Input Hypothesis, which stresses that simplified input along with contextual support is the key for comprehensible input.

The notion of negotiation is generally defined as a discussion to reach an agreement. Whenever a reader reads a text, which is analyzed silently, it involves three fundamental processes: interpretation, expression, and negotiation or their various combinations. Negotiation is seen as a type of real-life language use that is relevant to the learning purposes of the learners. It is likely to be the case in the context of a course of, business English, where negotiation can be expected to be identified as a relevant target language skill for the learners to develop in the classroom through simulated negotiations.

Hamzah and Ting (2010) pointed out both the importance and the role of the English language in the Information and Communication Technology world, educational field, and in real life situations for effective interaction. Nunan (2001) claimed that functioning in another language is generally characterized by the ability to speak that language. Learners evaluate their language learning success and their effectiveness of English courses based on their improvement in spoken language proficiency. Nugroho (2011) opined that classroom interaction has an inseparable role by experiencing new things which will help to learn it better in the classroom environment that has been gained by engaging in classroom activities. Interaction between learners and teacher influences learning success. Learning opportunities are more for those who are active in conversation through turn-taking than those who are passive.

Choudhury (2005) has explored the problem of active participation by incorporating the researchers' views and his own teaching experience. Teachers and learners together were the contributing source in managing the classroom interaction and at the same time managing learning opportunities. The findings have revealed that making the learners in active participation as much as possible but not in universal range for all learners learn best in the same way. Increasingly, researchers have looked outside the dominant paradigms in search of theoretical perspectives to support a redressing of the perceived imbalance between the cognitive and social aspects of language learning (Firth \& Wagner, 1997, 2007). Therefore, serious attention is necessary to ensure the negotiated classroom interaction among the learners for effective language learning. At the same time, negotiated interaction allows learners to know how it can contribute to L2 learning in the context of tertiary education in Bangladesh.

\section{ili. Methodology}

The primary objective of the study was to examine the impact of negotiated classroom interaction in English Language learning and teaching at the tertiary level of Bangladesh. The present research is about eliciting teachers' and learners' opinions with classroom observation about the effect of negotiated classroom interaction in English learning and teaching since they are the main variables of this study. Their views and opinions are very crucial to test the stated hypothesis.

The empirical method has been chosen which enhanced the study effectively. This method is a way of gaining knowledge using direct and indirect observation or experience. Empirical evidence (the record of one's direct observations or experiences) can be analyzed quantitatively or qualitatively. Through quantifying the evidence or making sense of it in qualitative form, one can answer empirical questions, which should be clearly defined and answerable with the collected evidence. Usually, a researcher has a certain theory regarding the topic under investigation. Based on this theory some statements, or hypotheses, will be proposed. From these hypotheses predictions about specific events are derived. These predictions can then be tested with a suitable experiment. Depending on the outcomes of the experiment, the theory on which the hypotheses and predictions were based will be supported or not, or may need to be modified and then subjected to further 
testing. (Goodwin 2005). To understand the implementation of different classroom techniques data have been collected individually from 150 students and 5 teachers of various levels in tertiary education in Bangladesh.

\section{Data Collection}

How the interactive activities are effective for the learner it is pointed out here. Getting a response to this category, a researcher found that most individual and group works are practiced in the classroom. On account of involving interactive activities by the teacher, the support is mostly group work. In the meantime, it is sometimes done in the classroom while doing the pair or group work according to the participants' response.

The data collected from teachers express different opinions considering the subject of negotiated interaction patterns occurring in the classroom, the aspects of impeding classroom interaction, and the effect of classroom interaction sustaining L2 learning. From this point of view, most of the teachers tell that they use the target language in a way where the learners also get enough opportunity to interact to put up the class lively. They have mentioned that the activities of role-playing, language game, individual work, pair work, and group work are maximum time practiced in the classroom. The convenient environment of practicing activities gradually shows the path of learners' L2 learning. They opine that learners get chances to talk with their partners and group members doing the work in pair or group which help them to be intelligible through negotiated interaction.

\section{Analysis}

In this part, the results of the study are discussed, focusing on how learners and teachers do the interactive activities to learn and teach English as SL/FL (SL-Second Language, FL- Foreign Language) in the context of tertiary education in Bangladesh.

In light of the research findings, it appears that most of the participants mention the necessary intelligibility of the target language as the medium of education. The basic differences between learners coming from bangle medium and English medium are regarding their more or less orientation. The value of knowing English is recognized in the society and there are positive attitudes towards learning it, as it is considered as beneficial for them for future success.

English learning in the tertiary classroom proceeds in a more conscious and deliberate way. Learners are generally exposed to grammatical structures explicitly, whether in $\mathrm{L} 2$ and come to accumulate some rule-based knowledge of the language. As it has been amply shown in a vast body of SLA research, explicit knowledge is not necessarily reflected in learners' spontaneous L2 use (Ellis, 2008). This study has found that teachers always encourage their learners to practice English in the classroom and outside the classroom. The study has also observed that few of the students practice English not only in the classroom but also outside.

It is widely believed that the success of ELT largely depends on the environment in which it is practiced. The study reveals that the students of tertiary education in Bangladesh have old and typical styled classrooms. In this situation, the teaching and learning cannot be carried out effectively rather it is reduced student's possibilities to interact for L2 learning and can also hamper the natural tendency to interact through practicing. Effective English language development requires explicit teaching features of English, it also requires ample, meaningful opportunities to use English (Goldenberg, 2008).

The study has found 'teachers' centered class (Direct or Grammar Translation Method) is one of the impediment aspects for negotiated interaction. Learners expect well trained and easy-going teachers for doing interacting activities in the classroom that should be practiced regularly. On the other hand, teachers suggest applying eclectic method in the classroom according to the topics. The effectiveness of teaching includes teachers' ability to prepare a lesson plan focusing on the teaching aim, administration, and the management of the class, and to work towards the aim with certain teaching strategies. Moreover, their requirement is modern teaching aids which play a very significant role in teaching and practicing English language skills covering or expanding content, and making their lessons easier and interesting by using the strategy of negotiated interaction.

The study has also noticed that in the case of using negotiated interaction teachers are supportive as well as friendly with the learners. The providing of necessary vocabularies and making the correct formation of sentences through negotiated interaction help learners to learn L2 perfectly. In Krashen”s (1985) affective filter hypothesis, teachers can make learners interested in L2 by introducing the diversification of teaching method applying vivid and humorous language to enlighten others, create a harmonious and convenient atmosphere for learning support students overcome their psychological barrier, and lower their anxiety and regularly introduce some culture and background knowledge of the target language. It is also mandatory to create more chances for learners to practice the target language in the classroom. Teachers have also to tolerate some small mistakes made by learners only if those mistakes do not affect the communication process because it can release pressure and strengthen their self-confidence. 


\section{Conclusions}

Enhancing the language skills of foreign or second language learners is a difficult task. It requires some experience and regular practice to improve the language accurately. Different types of classroom interactions as part of negotiated interaction are considerably vital to foreign language/Second language development. It is argued that interactions between teachers and learners will facilitate language development and will lead to better language learning. The analysis of the instruments showed that the learners are really given chances to use the language through engaging in negotiated interactions. Moreover, it is found that the teacher plays an important role to hold congenial environment, friendly, stress-free, and fearless with lower anxiety, which hastens interaction for learning. So in the end, we can conclude that negotiated interaction has various facilitating and beneficial effects in Second Language learning in tertiary education in Bangladesh.

\section{References Références Referencias}

1. Brown, H. D. (2001). Teaching by principles: An interactive approach to language pedagogy (3rd ed.). New York: Longman.

2. Creswell, J.W., \& Plano Clark, V. L. (2007). Designing and Conducting Mixed Methods Research. Thousand Oaks, CA: Sage Publications.

3. Ellis, R. (2003). Task-Based Language Learning and Teaching. Oxford: Oxford University Press.
4. Ellis, R. (2008). The study of second language acquisition (2nd ed.). Oxford: Oxford University Press.

5. Foster, P., \& Ohta, A. S. (2005). Negotiation for Meaning and Peer Assistance in Second Language Classrooms. Applied Linguistics, 26, 402-430.

6. Goldenberg, C. (2008). Teaching English Language Learners. American Educator, 32(2), 7-23, 42-44.

7. Harmer, J. (2001). The Practice of English Language Teaching. Pearson Education Ltd: Pearson.

8. Krashen, S. D. (1985). The Input Hypothesis: Issues and Implications. London: Longman.

9. Larsen-Freeman, D., \& Anderson, M. (2013). Techniques and Principles in Language Teaching (3rd ed.). Oxford University Press.

10. Mackey, A. (2013). The Conversational Interaction in Second Language Acquisition. Oxford: Oxford University Press.

11. Nunan, D. (1991). Language Teaching Methodology. London: Prentice Hall International.

12. Punch, K. F. (2005). Research Methods in Applied Linguistics. New York: Oxford University Press.

13. Rodney H. (2006). Studies in Second Language Acquisition. Cambridge University Press.

14. Vygotsky, L.S. (1978). Mind in Society. London: Harvard University Press.

15. Walter, E. (2013).Cambridge Advanced Learner's Dictionary $\left(4^{\text {th }}\right.$ ed). Cambridge University Press.

Appendix A

\section{Questionnaire for Students}

(The information will be used for academic purpose only. All personal information is going to be treated with strict confidentiality.)

You are requested to fill up the following information and put tick according to your argument.

1. How often do you interact with your classmates inside the classroom?

a. always b. often c. sometimes d. seldom e. never

2. How often your teacher gives you the opportunity to interact (give and take) with him/her?

a. always b. often c. sometimes d. seldom e. never

3. Which of the following interactive activities does your teacher do in the classroom?

a. individual work b. pair work c. group work d. chain drill e. choral drill

4. Who does most of the talk in the classroom?

a. teacher b. student c. teacher and student (Equally)

5. How often do you interact in English with your classmates outside the classroom?

a. always b. often c. sometimes d. seldom e. never

6. How often does your teacher involve you in pair/group work while taking the class?

a. always b. often c. sometimes d. seldom e. never

7. If you do not interact, it is because:

a. You are not talkative b. The topic is not interesting c. The teacher does not motivate

$\mathrm{d}$. The teacher fails to apply the teaching techniques e. You fear to make mistakes 


\section{Appendix B}

\section{Questions for Teacher}

1. Do you think students learn better if they work in pair/group? Why or why not?

2. How do you handle the aspects that hinder negotiated interaction in the classroom?

3. What type of interactive activities do you use in the classroom?

4. How do these activities help you and your students to develop English language? 